\title{
Study of antimicrobial resistance due to extended spectrum beta- lactamase-producing Escherichia coli in healthy broilers of Jabalpur
}

\author{
Arpita Shrivastav ${ }^{1}$, R. K. Sharma ${ }^{1}$, Y. P. Sahni ${ }^{2}$, Neeraj Shrivastav ${ }^{3}$, Vidhi Gautam ${ }^{1}$ and Sachin Jain ${ }^{1}$ \\ 1. Department of Veterinary Pharmacology \& Toxicology, College of Veterinary Science \& Animal Husbandry, Nanaji \\ Deshmukh Veterinary Science University, Jabalpur, Madhya Pradesh, India; 2. Director Research Services, Nanaji \\ Deshmukh Veterinary Science University, Jabalpur, Madhya Pradesh, India; 3. Department of Veterinary Microbiology, \\ College of Veterinary Science \& Animal Husbandry, Nanaji Deshmukh Veterinary Science University, Jabalpur, \\ Madhya Pradesh, India. \\ Corresponding author: Arpita Shrivastav, e-mail: arpitavet@gmail.com, \\ RKS: drrksvet2012@gmail.com,YPS: yashpal_sahni@yahoo.co.in, NS: neerajvet32@gmail.com, \\ VG: vidhi_modi20@yahoo.com, SJ: drsachinjain.vet@gmail.com \\ Received: 22-06-2016, Accepted: 07-10-2016, Published online: 16-11-2016
}

doi: 10.14202/vetworld.2016.1259-1263 How to cite this article: Shrivastav A, Sharma RK, Sahni YP, Shrivastav N, Gautam V, Jain S (2016) Study of antimicrobial resistance due to extended spectrum beta-lactamase-producing Escherichia coli in healthy broilers of Jabalpur, Veterinary World, 9(11): 1259-1263.

\begin{abstract}
Aim: To study the prevalence of antimicrobial resistance due to extended spectrum beta-lactamase (ESBL)-producing Escherichia coli in samples collected from the ceca of healthy broilers of poultry sale outlets (PSOs) Jabalpur.

Materials and Methods: A total of 400 cecal swab samples were taken randomly from freshly slaughtered poultry of 39 PSOs located at four different zones or areas of Jabalpur and were screened for the presence of ESBL-producing E. coli using standard methods. Further they were characterized phenotypically by standard methods.

Results: All the 400 samples were screened for $E$. coli producing ESBL enzyme. Among the samples positive for $E$. coli 135 were positive for ESBL E. coli giving an overall prevalence of $33.5 \%$.

Conclusion: This study related to the prevalence of ESBL-producing E. coli in healthy broilers in Jabalpur is indicative of antibiotic resistance prevalent in the healthy birds which are used for human consumption as well. It also signifies resistance prevalent against beta-lactam antibiotics including third and fourth generations of cephalosporins.
\end{abstract}

Keywords: cecal swab, Escherichia coli, extended spectrum beta-lactamase, healthy broilers, Jabalpur.

\section{Introduction}

Antimicrobial resistance, within a large range of infectious agents, is a rising health risk of broad concern to countries and multiple sectors. It not only menaces the effective prevention and treatment of an ever-increasing range of infections but also results in reduced efficacy of antibacterial drugs. In intensively reared poultry, antibiotics are administered to whole flocks rather than individual animals. In addition to this poultry farmer also use low doses of antibiotics as growth-promoting substances, which result in the high antibiotic selection pressure for resistance with relatively high proportion of resistant bacteria in poultry fecal flora.

Most resistant phenotypes present in animal populations are present in Escherichia coli, therefore commensal $E$. coli can be used as indicators of the Gram-negative species. During the passage through the intestine, these bacteria may transfer their resistance genes to host-adapted bacteria or to pathogens.

Copyright: Shrivastav, et al. Open Access. This article is distributed under the terms of the Creative Commons Attribution 4.0 International License (http://creativecommons.org/licenses/ by/4.0/), which permits unrestricted use, distribution, and reproduction in any medium, provided you give appropriate credit to the original author(s) and the source, provide a link to the Creative Commons license, and indicate if changes were made. The Creative Commons Public Domain Dedication waiver (http:// creativecommons.org/publicdomain/zero/1.0/) applies to the data made available in this article, unless otherwise stated.
All animals generally carry such indicator bacteria this is why trends in the occurrence of resistance, can be studied more accurately in indicator bacteria [1].

Beta-lactams (penicillins, cephalosporins, carbapenems, and monobactams) constitute the therapy of choice for some well-established practices and infections in veterinary medicine [2]. The third generation of cephalosporins has been associated with the emergence of beta-lactamases mediated bacterial resistance, which subsequently led to the development of extended spectrum beta-lactamase (ESBL)producing bacteria.

ESBLs have been defined as plasmid-encoded enzymes found in the Enterobacteriaceae [3], frequently in E. coli and Klebsiella pneumoniae, that confer resistance to a variety of beta-lactam antibiotics by catalyzing the hydrolysis of the beta-lactam ring of antibiotic specially oxyimino-cephalosporins, which can be inhibited by beta-lactamase inhibitors [4].

ESBL-producing organisms are frequently co- or multi-resistant, exhibiting resistance to other antimicrobial classes such as fluoroquinolones, aminoglycosides, and trimethoprim-sulfamethoxazole due to associated resistance mechanisms, which may be either chromosomally- or plasmid-encoded $[5,4]$.

During the last two decades, ESBL-producing Gram-negative bacilli have emerged as a major problem mainly due to the clonal expansion of producer 
organisms, the horizontal transfer of ESBL genes on plasmids [6]. Apart from therapy and prophylaxis, antibiotics are consumed to increase growth and feed efficiencies. There was a limited number of drugs sensitivity for these bacteria only and drug of choice is imipenem, followed by amikacin in injectable form. However, most probably in the near future, if this irrational use is not stopped, infection with that Gram-negative bacteria increase the rate of resistant to drugs that are now sensitive, resulting increase morbidity and mortality. Looking into the severity of the problem present study was undertaken for the prevalence and characterization of ESBL-producing E. coli in healthy broilers.

\section{Materials and Methods \\ Ethical approval}

No ethical approval was required as no live animals were used in this study. However, samples were collected as per standard sample collection methods following all aseptic precautions.

\section{Study site}

The study was conducted at Department of Veterinary Pharmacology and Toxicology, College of Veterinary Science and Animal Husbandry, Jabalpur, during January 2015 to January 2016.

\section{Sample collection}

A total of 400 cecal swab samples were collected randomly from 38 poultry sale outlets (PSOs) located at the various parts of Jabalpur. Sample collection area was divided into four zones east, west north and south and five areas were selected randomly in each zone area (Table-1). Samples were taken from the freshly slaughtered healthy broilers in an ice pack and taken to the lab. The properly labeled interlocked polythene bags containing the ceca were brought to the laboratory of the Department of Pharmacology and Toxicology,

Table-1: List of different sample collection areas of Jabalpur.

\begin{tabular}{lc}
\hline Name of the area & Number of samples \\
\hline North Zone 1 & 12 \\
North Zone 2 & 31 \\
North Zone 3 & 12 \\
North Zone 4 & 10 \\
North Zone 5 & 58 \\
South Zone 1 & 8 \\
South Zone 2 & 13 \\
South Zone 3 & 17 \\
South Zone 4 & 34 \\
South Zone 5 & 5 \\
East Zone 1 & 11 \\
East Zone 2 & 17 \\
East Zone 3 & 23 \\
East Zone 4 & 17 \\
East Zone 5 & 10 \\
West Zone 1 & 11 \\
West Zone 2 & 5 \\
West Zone 3 & 95 \\
West Zone 4 & 7 \\
West Zone 5 & 4 \\
Total samples & 400 \\
\hline
\end{tabular}

College of Veterinary Science and Animal Husbandry, Jabalpur for further study.

\section{Sample processing}

Taking all, the standard aseptic measures directly ceacal material were collected by incising the intact ceca with the help of sterile B.P.blade, later sterile swab swirled around and immediately transferred into the enrichment medium containing buffered peptone water $25 \mathrm{ml} / 5 \mathrm{~g}$ of sample for increasing the sensitivity and clonal expansion of the ESBL producing E. coli. Further, it was transferred into the M.H. broth supplemented with cefotaximes and cefpodoxime $(2 \mu \mathrm{g} / \mathrm{ml})$ and aztreonam $(4 \mu \mathrm{g} / \mathrm{ml})$ for the selective enrichment. Overnight enriched samples were streaked into the tryptone bile X-glucuronic agar plate supplemented with cefotaxime and aztreonam in the above-mentioned concentration for further selection of desired organisms. For further confirmation, the phenotypic characterization of ESBL producing $E$. coli was undertaken using standard methods combined disc diffusion test (CDDT) method, double disc synergy test method (DDST), and Ezy MIC strip method.

\section{Results and Discussion}

This study revealed the presence of ESBL producing E. coli in the healthy broilers of Jabalpur. Out of the total 400 cecal swab samples screened, 135 samples were found to be positive for ESBL giving an isolation prevalence percent of $33.5 \%$ as given in Table-1. Previously, different workers have reported the prevalence of similar ESBL-producing E. coli in healthy boilers.

In the present investigation initial screening in the buffered peptone water and M.H. broth and later in chromogenic medium specific for $E$. coli enriched with cefotaxime $(2 \mu \mathrm{g} / \mathrm{ml})$, cefpodoxime $(2 \mu \mathrm{g} / \mathrm{ml})$, and aztreonam $(4 \mu \mathrm{g} / \mathrm{ml})$ shown 135 samples positive out of 400 samples and here resistance to cefotaxime ceftazidime, and cefpodoxime whereas susceptibility to cefoxitin further confirms the presence of ESBL E.coli. In the present study entire sample collection area was divided into four zones which was North, South, East and West zone (Table-1). Broadly five areas were taken in each zone as mentioned in the Table-2. Highest prevalence was seen in the West zone (48.36\%), whereas lowest prevalence was seen in the South zone (25.97\%). In North and East zone the prevalence was in the range of $28.45 \%$ and $26.92 \%$ (Table-2). Different poultry sale outlets were further included in these zones which showed a wide variation in the results (Table-3). Perusal of the results revealed that at some areas there was $100 \%$ prevalence of ESBL E. coli isolates, whereas other areas exhibited lower range of prevalence $(0-30 \%)$. Our findings simulate with the results obtained by Hasan et al. [7] in Bangladesh and adjoining areas of India where they observed an overall prevalence of ESBL-producers as $30 \%$ in poultry and domestic birds, $27 \%$ in wild birds and 59\% prevalence was seen in hospitals and 
Table-2: Percent prevalence of ESBL E. coli from different collection areas of Jabalpur.

\begin{tabular}{lcccc}
\hline Name of the area & Number of samples & Positive samples & Negative samples & Percent prevalence \\
\hline North Zone 1 & 12 & 7 & 5 & 58.3 \\
North Zone 2 & 31 & 2 & 29 & 6.5 \\
North Zone 3 & 12 & 8 & 4 & 66.7 \\
North Zone 4 & 10 & 9 & 1 & 90.0 \\
North Zone 5 & 58 & 9 & 0 & 15.5 \\
South Zone 1 & 8 & 8 & 9 & 100.0 \\
South Zone 2 & 13 & 4 & 10 & 30.8 \\
South Zone 3 & 17 & 7 & 34 & 41.2 \\
South Zone 4 & 34 & 0 & 4 & 0.0 \\
South Zone 5 & 5 & 1 & 10 & 20.0 \\
East Zone 1 & 11 & 1 & 10 & 9.1 \\
East Zone 2 & 17 & 7 & 17 & 41.2 \\
East Zone 3 & 23 & 5 & 2 & 21.7 \\
East Zone 4 & 17 & 0 & 5 & 0.0 \\
East Zone 5 & 10 & 8 & 5 & 80.0 \\
West Zone 1 & 11 & 6 & 42 & 54.5 \\
West Zone 2 & 5 & 0 & 7 & 0.0 \\
West Zone 3 & 95 & 53 & 4 & 0.0 \\
West Zone 4 & 7 & 0 & 265 & 0.0 \\
West Zone 5 & 4 & 0 &
\end{tabular}

$\mathrm{ESBL}=$ Extended spectrum beta-lactamase, $E$. coli=Escherichia coli

Table-3: Percent prevalence of ESBL E. coli in different PSOs of Jabalpur.

\begin{tabular}{|c|c|c|c|c|c|}
\hline Zone & Name of PSO & $\begin{array}{c}\text { Number of samples } \\
\text { collected }\end{array}$ & $\begin{array}{c}\text { Number of positive } \\
\text { samples }\end{array}$ & $\begin{array}{c}\text { Number of negative } \\
\text { samples }\end{array}$ & Percent prevalence \\
\hline \multirow[t]{11}{*}{ North } & PSO 1 & 12 & 7 & 5 & 58.3 \\
\hline & PSO 2 & 1 & 1 & 0 & 100.0 \\
\hline & PSO 3 & 9 & 8 & 1 & 88.8 \\
\hline & PSO 4 & 8 & 0 & 8 & 0.00 \\
\hline & PSO 5 & 16 & 2 & 14 & 12.5 \\
\hline & PSO 6 & 7 & 3 & 4 & 42.85 \\
\hline & PSO 7 & 28 & 1 & 27 & 3.57 \\
\hline & PSO 8 & 29 & 8 & 21 & 27.58 \\
\hline & PSO 9 & 7 & 2 & 1 & 28.57 \\
\hline & PSO 10 & 3 & 3 & 0 & 100.0 \\
\hline & PSO 11 & 2 & 0 & 2 & 0.00 \\
\hline \multirow[t]{7}{*}{ South } & PSO 1 & 8 & 8 & 0 & 100.0 \\
\hline & PSO 2 & 10 & 2 & 2 & 20 \\
\hline & PSO 3 & 3 & 0 & 3 & 0.00 \\
\hline & PSO 4 & 5 & 0 & 5 & 0.00 \\
\hline & PSO 5 & 6 & 3 & 3 & 50.0 \\
\hline & PSO 6 & 11 & 2 & 9 & 18.1 \\
\hline & PSO 7 & 34 & 0 & 34 & 0.00 \\
\hline \multirow[t]{9}{*}{ East } & PSO 1 & 17 & 0 & 17 & 0.00 \\
\hline & PSO 2 & 10 & 5 & 5 & 50.0 \\
\hline & PSO 3 & 4 & 0 & 4 & 0.00 \\
\hline & PSO 4 & 4 & 4 & 0 & 100.0 \\
\hline & PSO 5 & 9 & 3 & 6 & 33.3 \\
\hline & PSO 6 & 6 & 5 & 1 & 83.3 \\
\hline & PSO 7 & 3 & 1 & 2 & 33.3 \\
\hline & PSO 8 & 14 & 0 & 14 & 0.00 \\
\hline & PSO 9 & 12 & 2 & 10 & 16.6 \\
\hline \multirow[t]{12}{*}{ West } & PSO 1 & 4 & 0 & 4 & 0.00 \\
\hline & PSO 2 & 7 & 6 & 1 & 85.7 \\
\hline & PSO 3 & 5 & 2 & 3 & 40 \\
\hline & PSO 4 & 15 & 2 & 13 & 13.3 \\
\hline & PSO 5 & 10 & 8 & 2 & 80.0 \\
\hline & PSO 6 & 5 & 2 & 3 & 40.0 \\
\hline & PSO 7 & 5 & 0 & 5 & 0.00 \\
\hline & PSO 8 & 39 & 33 & 6 & 84.61 \\
\hline & PSO 9 & 19 & 11 & 8 & 57.89 \\
\hline & PSO 10 & 2 & 1 & 1 & 50.0 \\
\hline & PSO 11 & 7 & 0 & 7 & 0.00 \\
\hline & PSO 12 & 4 & 0 & 4 & 0.00 \\
\hline
\end{tabular}

PSO=Poultry sale outlet, $\mathrm{ESBL}=$ Extended spectrum beta-lactamase, $E$. coli=Escherichia coli 
community people, they further concluded that ESBLproducing bacterial species diversity was highest in poultry and humans were the best ESBL carriers.

A wide range of prevalence from $0 \%$ to $100 \%$ in the present investigation also revealed that occurrence of this varied range of resistant isolates does not correlates only with direct use of antibiotics, but even other species of birds and humans, can carry antibiotic resistance traits, including ESBL-producers and bring resistance in broiler birds, as these ESBL-producers have already spilled over into the environment [8]. A study performed by van den Bogaard et al. [9] indicated that transmission of resistant clones and resistance plasmids of $E$. coli from poultry to humans commonly occurs. In this study, the prevalence of resistance in fecal $E$. coli in broilers and turkeys was analyzed, and the highest prevalence of resistance was detected in turkey samples, closely followed by those from broilers.

In a study conducted in 14 different chicken farms in Henan Province in China 51 nonreplicate ESBL-producing E. coli were isolated. 31 of the 51 isolates were positive for an ESBL phenotype and 29 of these isolates carried one or more Bla genes [10]. Another study on Belgian broiler farms, concluded that risk factors associated with the occurrence of ESBL-producing $E$. coli besides the usage of any particular antimicrobial like cephalosporins, also included generic antimicrobial use $[3,11]$ the cleanliness of the environment, the lack of acidification of drinking water, the application of more than three feed changes during the production cycle, the breed and the litter material that is used $[12,13]$. The aforesaid findings add another aspect to our study that, in spite of obtaining birds from same sources prevalence varied to great extent because at the level of farm management, ESBL producing bacteria may enter and proliferate in a farm through the stocking of new animals, exposure to contaminated air, through water or feed, insect or rodent vectors, human-to-animal and animal-to-animal transmission. Moreover, chemicals used in animal production - such as antiseptics, disinfectants, and metals - could play a role in the appearance of such resistant isolates [3,14-16].

In the phenotypic characterization by the CDDT method, out of 135 samples, all the samples were found to be positive and none of the samples were negative calculating a percent isolation of $100 \%$. In DDST method out of, 135 samples screened 115 samples shown the positive results. Phenotypic characterization was also done by Ezy MIC strip for the confirmation of ESBL producers. Ceftazidime and ceftazidime + clavulanic acid containing strip was used. Out of the total samples screened for ESBL production only 84 samples depicted positive results by Ezy MIC strip (Table-4). The phenotypic characterization by CDDT method revealed most of the samples were resistant to cefotaxime, cefpodoxime and few were resistant toward ceftazidime these findings correlates with the European Union recommendations as
Table-4: Comparative sensitivity of methods of phenotypic characterization of ESBL E. coli.

\begin{tabular}{|c|c|c|c|}
\hline Type of samples & $\begin{array}{l}\text { CDDT } \\
\text { method }\end{array}$ & $\begin{array}{l}\text { DDST } \\
\text { method }\end{array}$ & Ezy MIC strip \\
\hline Positive samples & 135 & 115 & 84 \\
\hline Negative samples & 0 & 20 & 51 \\
\hline $\begin{array}{l}\text { Total number of } \\
\text { samples }\end{array}$ & 135 & 135 & 135 \\
\hline Percent sensitivity & 100 & 85 & 62 \\
\hline Chi-square value & $67.7 * *$ & & \\
\hline
\end{tabular}

ESBL producers are usually resistant to cefotaxime, variably resistant to ceftazidime, and susceptible to cefoxitin [16]. Thus, in reference to the current recommendations [5] cefotaxime was included as marker for present investigations. Resistance to ESBL-producing isolates testing with ceftazidime would improve the ability to identify the organism and also enhance the sensitivity to identify the isolates producing certain beta-lactamases belonging to SHV and TEM families of enzymes which are ceftazidimases and have much lower activity than cefotaximases. As per the recommendation of the European Union use of specific chromogenic medium avoided the identification of the colonies belonging to the other species within Enterobacteriaceae. Enrichment at this level with cephalosporins as stated in the scientific report of EFSA, influence the bacterial conjugation, exchange of resistance plasmids and increase the sensitivity of the method [5]. This correlates with our findings as initial screening gave 135 samples positive for ESBL E. coli, and all the samples showed positive results in the phenotypic characterization by CDDT method.

\section{Conclusion}

Animal was apparently healthy during the slaughter and was used for the human consumption; the prevalence of ESBL-producing E. coli which is a commensal bacteria indicating the problem of antibiotic resistance against beta-lactam antibiotic group which even includes third and fourth generation cephalosporins. CDDT method was found to be most sensitive among the three and most of the isolates were resistant toward cefotaxime discs and Ezy MIC strip method was the least the reason behind this was Ezy strip method is based on MIC values and the range of MIC could have been beyond the MIC range of the strip. As these organisms carry their genes on the plasmid due to horizontal gene transfer co- or multi-resistance against other antibiotics are also possible which could be an alarming sign specially for the poultry and human in contact with the birds.

\section{Authors' Contributions}

AS designed and planned this research work collected the samples and executed the entire work RKS 
and YPS guided and monitored the entire research work. NS contributed in the collection of samples and also helped in the designing of work plan VG and SJ analyzed the data and were involved in the experiment. All authors contributed equally in preparation and revision of the manuscript. All authors read and approved the final manuscript.

\section{Acknowledgments}

The authors are highly thankful to the Dean, College of Veterinary Science and Animal Husbandry, Jabalpur and Director Research Services, Nanaji Deshmukh Veterinary Science and Animal Husbandry, Jabalpur, Madhya Pradesh, India, for providing necessary financial assistance and instrumentation facilities to carry out this research work.

\section{Competing Interests} interest.

The authors declare that they have no competing

\section{References}

1. European Food Safety Authority, (EFSA). (2012) Technical specifications for the analysis and reporting of data on antimicrobial resistance in the European Union Summary Report. EFSA J., 10(2): 2587.

2. Nóbrega, D.B. and Brocchi, M. (2014) An overview of extended-spectrum beta-lactamases in veterinary medicine and their public health consequences. J. Infect. Dev. Ctries., 8(8): 954-960.

3. European Food Safety Authority. (2011d) Scientific Opinion of the Panel on Biological Hazards (BIOHAZ) on the public health risks of bacterial strains producing extended-spectrum $\beta$-lactamases and/or AmpC $\beta$-lactamases in food and food-producing animals. EFSA J., 9(8): 2322.

4. Paterson, D.L. and Bonomo, R.A. (2005) Extendedspectrum beta-lactamases: A clinical update. Clin. Microbiol. Rev., 18: 657-686.

5. Jacoby, G.A. and Munoz-Price, L.S. (2005) The new beta-lactamases. N. Engl. J. Med., 352: 380-391.

6. Paterson, D.L., Hujer, K.M., Hujer, A.M., Yeiser, B., Bonomo, M.D. and Rice, L.B. (2003) Extended-spectrum beta-lactamases in Klebsiella pneumonia bloodstream isolates from seven countries: Dominance and widespread prevalence of SHV- and CTX-M-type beta-lactamases. Antimicrob. Agents Chemother., 47: 3554-3560.

7. Hasan, B., Faruque, R., Drobni, M., Waldenström, J., Sadique, A., Ahmed, K.U., Islam, Z., Parvez, M.B., Olsen, B. and Alam, M. (2011) High prevalence of antibiotic resistance in pathogenic Escherichia coli from large and small scale poultry farms in Bangladesh. Avian Dis., 55(4): 689-692.

8. Witte, W. (1998) Medical consequences of antibiotic use in agriculture. Science, 279: 996-997.

9. van den Bogaard, A.E., London, N., Driessen, C. and Stobberingh, E.E. (2001) Antibiotic resistance of faecal Escherichia coli in poultry, poultry farmers and poultry slaughterers. J. Antimicrob. Chemother., 47: 763-771.

10. Yuan, L., Jian-Hua, L., Gong-Zheng, H., Yu-Shan, P., ZhiMing, L., Juan, M.O. and Yong-Jun, W. (2009) Molecular characterization of extended-spectrum b-lactamase-producing Escherichia coli isolates from chickens in Henan Province, China. J. Med. Microbiol., 58: 1449-1453.

11. Dheilly, A., LeDevendec, L., Mourand, G., Bouder, A., Jouy, E. and Kempf, I. (2012) Resistance gene transfer during treatments for experimental avian colibacillosis. Antimicrob. Agents Chemother., 56: 189-196.

12. Persoons, D., Haesebrouck, F., Smet, A., Herman, L., Heyndrickx, M., Martel, A., Catry, B., Berge, A.C., Butaye, P. and Dewulf, J. (2010) Risk factors for ceftiofur resistance in Escherichia coli from Belgian broilers. Epidemiol. Infect., 139: 765-771.

13. Smet, A., Martel, A. and Persoons, D. (2010) Broadspectrum beta-lactamases among Enterobacteriaceae of animal origin: Molecular aspects, mobility and impact on public health. FEMS Microbiol. Rev., 34: 95-316.

14. Aarestrup, F.M. and Hasman, H. (2004) Susceptibility of different bacterial species isolated from food animals to copper sulphate, zinc chloride and antimicrobial substances used for disinfection. Vet. Microbiol., 100: 83-89.

15. Cavaco, L.M., Hasman, H., Stegger, M., Andersen, P.S., Skov, R., Fluit, A.C., Ito, T. and Aarestrup, F.M. (2010) Cloning and occurrence of $c z r \mathrm{C}$, a gene conferring cadmium and zinc resistance in methicillin resistant Staphylococcus aureus CC398 isolates. Antimicrob. Agents Chemother, 54: 3605-3608.

16. Hasman, H. and Aarestrup, F.M. (2002) $t c r$ B, a gene conferring transferable copper resistance in Enterococcus faecium: Occurrence, transferability, and linkage to macrolide and glycopeptides resistance. Antimicrob. Agents Chemother., 46: 1410-1416. 